\title{
MECHANICAL PROPERTIES OF WN43 MAGNESIUM ALLOY PREPARED BY SPARK PLASMA SINTERING
}

\author{
1,2Michal KNAPEK, ${ }^{1}$ Peter MINÁRIK, ${ }^{1}$ Adam GREŠ, ${ }^{1}$ Mária ZEMKOVÁ, \\ ${ }^{3}$ Jakub CINERT, ${ }^{1}$ Robert KRÁL \\ ${ }^{1}$ Department of Physics of Materials, Faculty of Mathematics and Physics, Charles University, Prague, \\ Czech Republic, EU \\ knapek@karlov.mff.cuni.cz, peter.minarik@mff.cuni.cz, adam.gres1@gmail.com, \\ 1zemkova.maria1@gmail.com, rkral@met.mff.cuni.cz \\ ${ }^{2}$ Nuclear Physics Institute, The Czech Academy of Sciences, Řež, Czech Republic, EU \\ 3Institute of Plasma Physics, The Czech Academy of Science, Prague, Czech Republic, EU \\ cinert@ipp.cas.cz
}

https://doi.org/10.37904/metal.2019.950

\begin{abstract}
The spark plasma sintering (SPS) method was used to prepare bulk materials form WN43 magnesium alloy atomized powder. Compression tests were carried out in order to investigate the effect of different sintering regimes $\left(10 \mathrm{~min}\right.$ at 400,450 , or $500{ }^{\circ} \mathrm{C}$ ) on the mechanical properties of the material. Furthermore, complementary in-situ acoustic emission (AE) recording was employed to reveal the dynamics of deformation processes during compression. It was shown that by increasing the sintering temperature, the ultimate compressive strength and ductility were significantly improved. The AE data and microstructure observations suggest that pronounced twin nucleation takes place around the yield point whereas twin growth and dislocation activity are the dominant deformation mechanisms in the later stages of deformation.
\end{abstract}

Keywords: Spark plasma sintering, magnesium, deformation, twinning, acoustic emission

\section{INTRODUCTION}

Magnesium alloys exhibit a number of distinctive properties, such as high strength-to-weight ratio, relatively low elastic modulus, non-toxicity, and biodegradability, which open new possibilities for practical, particularly biomedical, applications. For this reason, the studies of magnesium-based materials have intensified in the last decade. Research in the field of biological implants has been growing significantly and new types of alloys are being persistently developed. Desirable biomechanical properties have been reported for magnesium alloys containing rare earth (RE) elements, i.e. WE43 and LAE442 alloys (W - yttrium, E - rare earths, A - aluminum, L - lithium) [1-4]. Both aluminum and RE additions are known to improve the mechanical properties and to support grain refinement and creep resistance. Reduction of grain size was found to be an important factor for the improvement of corrosion resistance of biomedical magnesium alloys. Ultrafine-grained (UFG) microstructures can be produced using methods of severe plastic deformation (SPD). Another, often more effective way to produce the UFG material is the sintering of atomized material particles. Powder particles can be consolidated by many different techniques, typically by hot isostatic pressing and extrusion. However, these techniques involve long exposure times at high temperatures, leading to undesirable coarsening of the initial UFG microstructures. These drawbacks can be eliminated using the modern spark plasma sintering (SPS) method [5], which operates at considerably lower sintering times and temperatures. However, there are only a limited number of works focusing on SPS production of magnesium [6,7].

It this work, mechanical properties of a novel WN43 alloy produced by the SPS technique were investigated. Pure neodymium (N) was used instead of the RE mischmetal present in the commercial WE43 alloys as neodymium was shown to have the most beneficial effect on the corrosion resistance of $\mathrm{Mg}$ alloys among all 
RE elements [8]. Conventional compression tests were carried out in combination with in-situ acoustic emission (AE) recording in order to study the mechanical performance of alloy compacted at different temperatures $\left(400,450\right.$, and $\left.500{ }^{\circ} \mathrm{C}\right)$ for $10 \mathrm{~min}$. The acoustic emission data helped to reveal the evolution of active deformation mechanisms, which were further confirmed by the scanning electron microscopy (SEM) by means of electron backscatter diffraction (EBSD) observations.

\section{MATERIALS AND METHODS}

The WN43 (Mg-4Y-3Nd) magnesium alloy was cast at the Helmhoz-Zentrum Geesthacht, Germany. The cast billets were machined, remelted and gas-atomized at the Clausthal University of Technology, Germany. Celllike structure of secondary phase was observed, as shown in Figure 1, which was identified as Mg3Nd by the EDX and XRD experiments (not shown here). Furthermore, no Y-containing phases were found, therefore, $Y$ is considered to be dissolved in the Mg matrix.

Powder particles of size $<100 \mu \mathrm{m}$ were sintered using the spark plasma sintering (SPS) system - type 10-4, Thermal technology LLC. Sintering was performed at three temperatures $-400{ }^{\circ} \mathrm{C}, 450^{\circ} \mathrm{C}$, and $500{ }^{\circ} \mathrm{C}$ for 10 min with applied pressure of $100 \mathrm{MPa}$.

The compression tests were carried out using the universal testing machine Instron 5882 at room temperature with an initial strain rate of $10^{-3} \mathrm{~s}^{-1}$. Three samples with dimensions of $5 \mathrm{~mm} \times 3 \mathrm{~mm} \times 3 \mathrm{~mm}$ were cut from each material from the central part of compacted pellet. The loading direction was perpendicular to the direction of applied load during the production of pellets. Deformation tests were complemented by concurrent $\mathrm{AE}$ recording. The AE acquisition was performed using the Physical Acoustics Corporation (PAC) PCl-2 board, PAC preamplifier 2/4/6 with a gain set to $60 \mathrm{~dB}$ and the broadband AE sensor PAC Pico attached to the deformation grip with a plastic clip. Good acoustic contact between the grip and the sensor was facilitated by the vacuum grease Apiezon $\mathrm{M}$. The AE parameters were obtained using a standard hit-based processing with the threshold level set to $23 \mathrm{~dB}$.

The microstructure observations were performed using the scanning electron microscope (SEM) ZEISS Auriga Compact equipped with EDAX EBSD camera. The samples for SEM were mechanically polished down to 0.25 $\mu \mathrm{m}$ diamond paste. The Samples for EBSD were additionally ion-polished using Leica EM RES102 ion beam milling system.

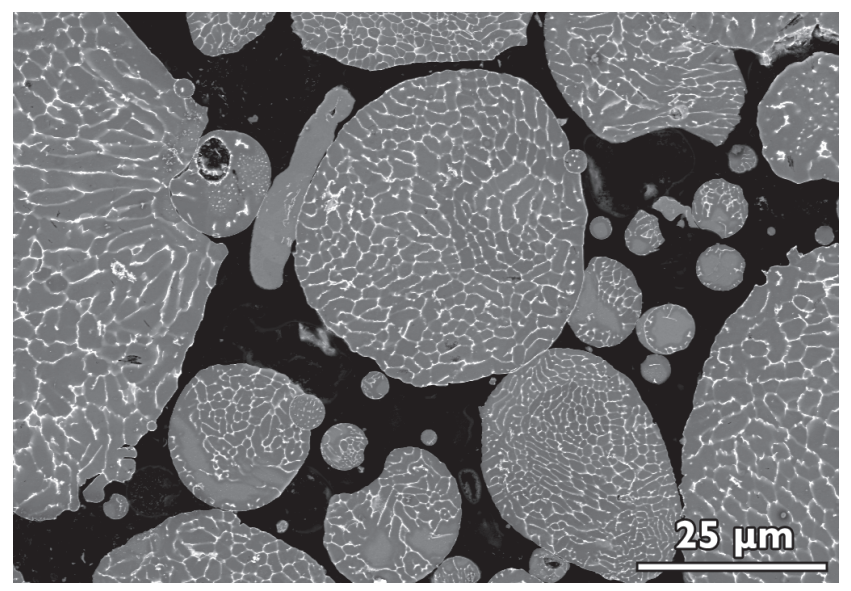

Figure 1 The microstructure (SEM) of the atomized WN43 particles

\section{RESULTS AND DISCUSSION}

The SEM microstructure observations in Figure 2 demonstrate the effect of the sintering temperature (400, 450 , or $500{ }^{\circ} \mathrm{C}$ ) on the microstructure, particularly on the compactness and secondary phases distribution. 
After the sintering at $400{ }^{\circ} \mathrm{C}$, the microstructure contained residual pores, which negatively affected mechanical properties, as will be shown later. Distribution of the $\mathrm{Mg}_{3} \mathrm{Nd}$ phase changed only slightly and mainly the disruption of the initial cell-like distribution accompanied by coarsening of individual particles was observed. Sintering at $450{ }^{\circ} \mathrm{C}$ resulted in a substantial reduction of porosity. In addition, considerable transfer of the secondary phase from the inner parts of individual powder particles to the particle boundaries was witnessed. This process was even stronger during sintering at $500{ }^{\circ} \mathrm{C}$. At this highest sintering temperature, no porosity was observed in the SEM micrographs, therefore, this material is considered as fully compacted. The EBSD investigations showed that the sintering temperature influenced considerably the grain structure as well. While the average grain size increased only slightly $\left(400{ }^{\circ} \mathrm{C}-16 \mu \mathrm{m}, 450{ }^{\circ} \mathrm{C}-17 \mu \mathrm{m}, 500{ }^{\circ} \mathrm{C}-19 \mu \mathrm{m}\right)$, the grain distribution became more. Such effect was also observed in the previous study on AE42 magnesium alloy produced by SPS [6].

The compression true stress-true strain curves presented in Figure 3 demonstrate the impact of different SPS temperature on the material mechanical properties. Only one sample is shown for each condition, as the mechanical (as well as $\mathrm{AE}$ ) response was practically identical across the samples of each set. It is evident that increasing sintering temperature resulted in a significant enhancement of ductility $\left(400{ }^{\circ} \mathrm{C}-3 \%, 450{ }^{\circ} \mathrm{C}\right.$ $-9 \%, 500{ }^{\circ} \mathrm{C}-17 \%$ ) and mechanical strength $\left(400{ }^{\circ} \mathrm{C}-195 \mathrm{MPa}, 450{ }^{\circ} \mathrm{C}-242 \mathrm{MPa}, 500{ }^{\circ} \mathrm{C}-353 \mathrm{MPa}\right) . \mathrm{On}^{\circ}$ the other hand, the yield strength remained practically unaffected within the experimental uncertainty. The sigmoidal "s-shaped" deformation curves of the material sintered at 450 and $500{ }^{\circ} \mathrm{C}$ indicate that twinning should be one of the active deformation mechanisms so as to fulfill the von Mises criterion [9].
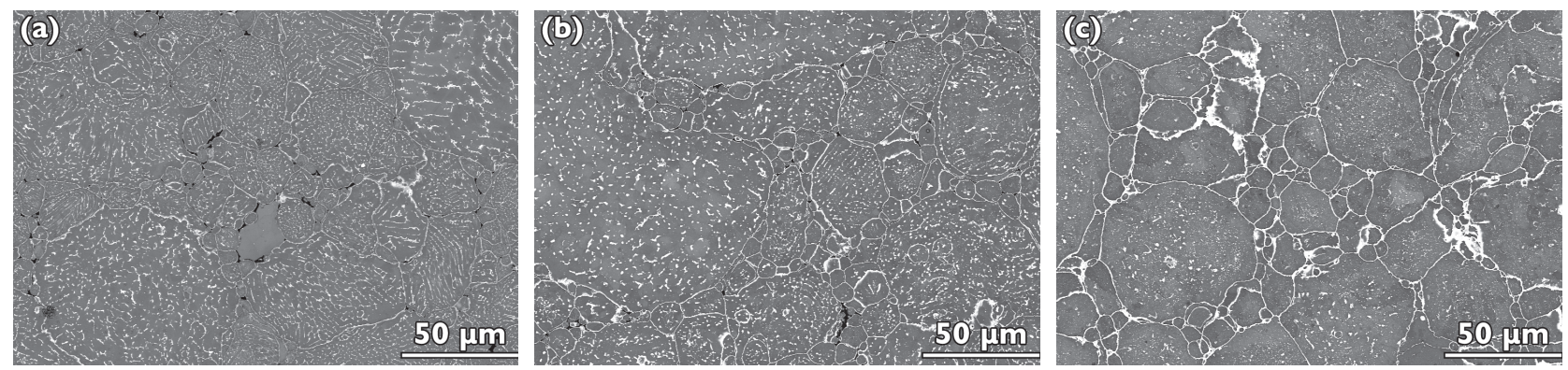

Figure 2 The SEM microstructure observations of the bulk WN43 samples prepared by SPS operating for 10 $\min$ at a) $400{ }^{\circ} \mathrm{C}$, b) $450{ }^{\circ} \mathrm{C}$, and c) $500{ }^{\circ} \mathrm{C}$

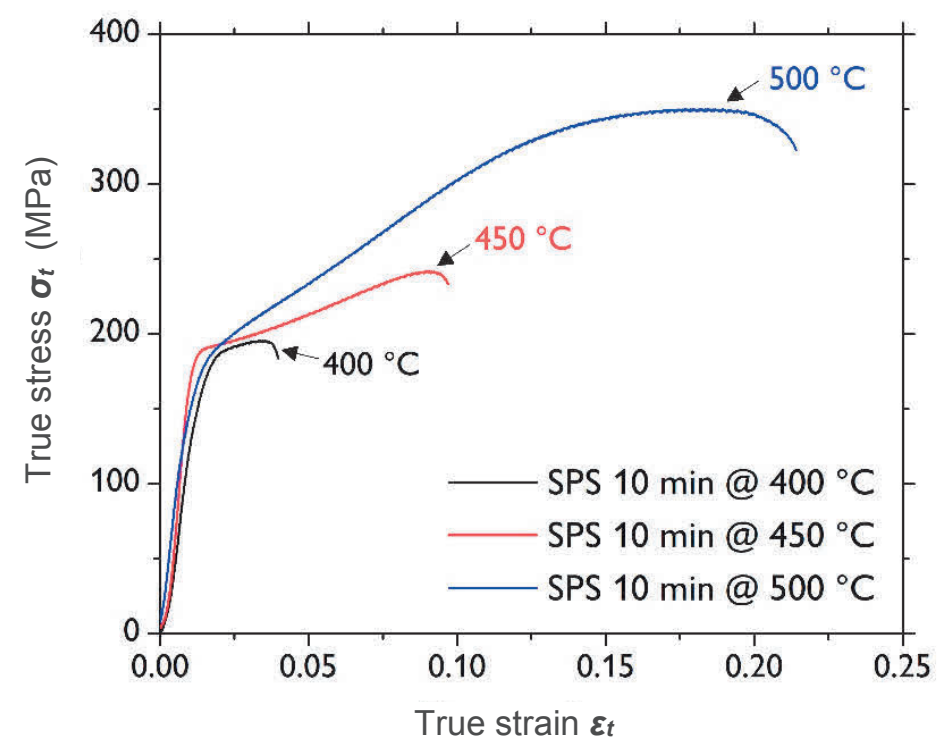

Figure 3 The compression curves of the bulk WN43 samples prepared by SPS 
In order to obtain detailed information on the deformation dynamics, compression tests presented in Figure 3 were complemented by the in-situ AE recording. The AE event parameters (counts per event and signal amplitudes) recorded during individual compression tests of the WN43 samples sintered at different temperatures are shown in Figure 4. The AE activity starts to appear even in the quasi-elastic stage of loading and is most pronounced around the yield point for all samples. It was shown that true elasticity might not be present in many Mg-based materials due to microplasticity [10], resulting in AE signals reflecting such plastic microstructural changes. Significant $\mathrm{AE}$ in the vicinity of the yield point of $\mathrm{Mg}$ alloys is typically related to the cooperative dislocation activity in the basal planes and to the formation of mechanical twins [11]. Past the yield point, the $A E$ activity gradually diminishes and only sporadic $A E$ signals occur after the compressive strain reaches $\sim 6 \%$ ( $t=60 \mathrm{~s}$, as the strain rate of $10^{-3} \mathrm{~s}^{-1}$ was used). It is worth noting that this behavior holds for both samples sintered at 450 and $500{ }^{\circ} \mathrm{C} \mathrm{AE}$, and similar trend is also observed for the sample sintered at $400{ }^{\circ} \mathrm{C}$, even though its fracture takes place as early as around $4.5 \%(t=45 \mathrm{~s})$, i.e. when continuous $\mathrm{AE}$ signals are still present. This result indicates that the $A E$ activity reflects the microstructural changes as a function of absolute stress or strain rather than a function of relative strain before fracture. It the later stages of deformation of ductile samples $\left(450\right.$ and $500{ }^{\circ} \mathrm{C}$ ) the $\mathrm{AE}$ signals almost vanishes, most likely as a result of changes in the deformation mechanisms. It was shown that increasing dislocation density at higher strains reduces the mean free path of new dislocations, which, in turn, results in the reduced energy and collectiveness of the overall dislocation activity (thus considerably weakening the AE response). Moreover, it was reported that only nucleation of mechanical twins is a good source of $A E$, whereas twin thickening during latter stages of deformation is, by means of $\mathrm{AE}$, practically silent [12].

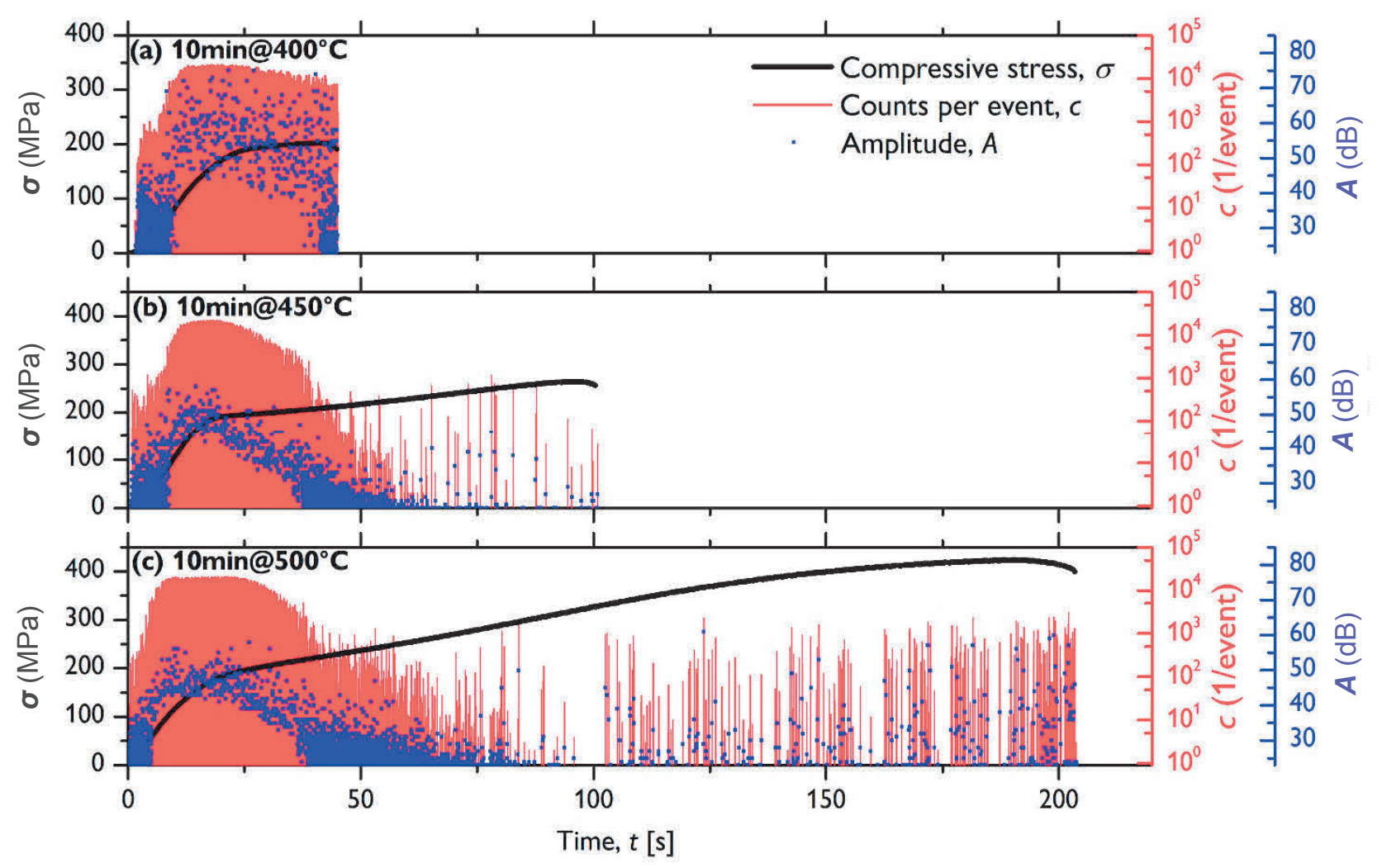

Figure 4 The AE response of the bulk WN43 samples prepared by SPS operating for 10 min at a) $400{ }^{\circ} \mathrm{C}$, b) $450{ }^{\circ} \mathrm{C}$, and c) $500{ }^{\circ} \mathrm{C}$ 

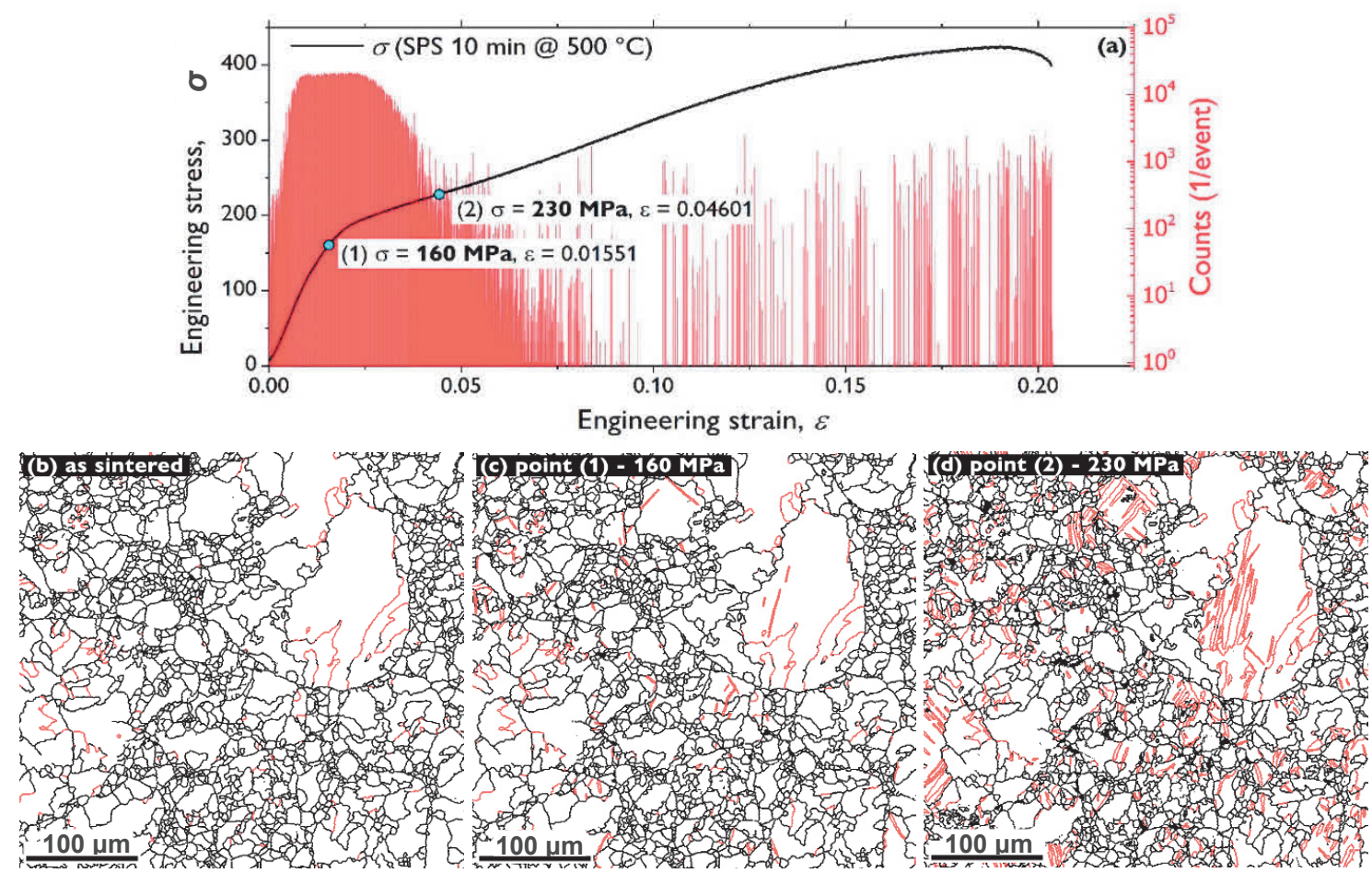

Figure 5 a) Selected points (1) and (2) during compression of the WN43 sample prepared by SPS for 10 min at $500{ }^{\circ} \mathrm{C}$; b) EBSD grain boundary maps of as sintered material, c) of the same sample predeformed to 160 $\mathrm{MPa}$ (point 1), and d) to $230 \mathrm{MPa}$ (point 2), showing the evolution of mechanical twinning. High angle grain boundaries (misorientation $>15^{\circ}$ ) are marked in black and $\{10 \overline{1} 2\}<10 \overline{1} 0>$ extension twin boundaries are marked in red.

To further confirm the $\mathrm{AE}$ results with respect to the deformation dynamics, compression test of the most compact sample $\left(500^{\circ} \mathrm{C}\right.$ ) was repeated and interrupted at two stress levels - (1) $160 \mathrm{MPa}$ (i.e. slightly before the yield point) and (2) $230 \mathrm{MPa}$ (i.e. when the AE significantly diminishes), as can be seen in Figure $\mathbf{5 a}$. After the test interruptions, the microstructure of surface area was examined using EBSD in terms of the grain boundary maps. Figure $\mathbf{5 b}$ shows the microstructure of as-sintered sample, i.e. before testing. Figures $\mathbf{5 c}$ and $\mathbf{5 d}$ display the evolution of grain boundaries, where red color denotes $\{10 \overline{1} 2\}<10 \overline{1} 0>$ extension twin boundaries identified based on the known twin parent/daughter orientation relation. It is evident that some twins are already present in the as sintered material (Figure 5b), most likely as a result of the pressure (100 $\mathrm{MPa}$ ) applied during production. At $160 \mathrm{MPa}$ (point (1)) first thin, freshly nucleated twins occurred, giving rise to the AE activity (cf. Figure 4). Later, at $230 \mathrm{MPa}$ (point (2)) lots of twins are already present in the microstructure and the thickening manifestedly takes place, accounting for the reduction of AE. Furthermore, it is known that dislocation density rises with increasing strain and the resulting dislocation networks can obstruct further dislocation slip activity [11]. Dislocations can move only short distances and become pinned at the obstacles where they require high energies to be released in a burst-like manner. Subsequently, these dislocation avalanches give rise to sporadic AE signals of high amplitudes in the later stages of compression, as was observed in Figures $\mathbf{4 b}$ and $\mathbf{4 c}$.

\section{CONCLUSIONS}

The SPS method was successfully employed to prepare bulk material from the atomized WN43 magnesium powder. The results of the compression tests performed on the materials prepared using different sintering regimes ( $10 \mathrm{~min}$ at 400,450 , or $500{ }^{\circ} \mathrm{C}$ ) showed substantial dependence of the mechanical properties on the 
sintering temperature; the mechanical strength increased from $195 \mathrm{MPa}\left(400^{\circ} \mathrm{C}\right)$ to $242 \mathrm{MPa}\left(450{ }^{\circ} \mathrm{C}\right)$ and to $353 \mathrm{MPa}\left(500{ }^{\circ} \mathrm{C}\right)$ and the strain-to-fracture improved from $3 \%\left(400{ }^{\circ} \mathrm{C}\right)$ to $9 \%\left(450{ }^{\circ} \mathrm{C}\right)$, and to $17 \%$ $\left(500{ }^{\circ} \mathrm{C}\right)$. The $\mathrm{AE}$ results and microstructure observations confirmed that distinctive twin nucleation is the main deformation mechanism around the yield point, producing strong continuous AE signals. In the later stages of compression, twin growth and dislocation slip become the dominant deformation mechanisms, leading to diminishing $A E$ as (i) twin thickening does not produce detectable $A E$ and, in addition, (ii) the mean free path of dislocations is reduced with increasing strain.

\section{ACKNOWLEDGEMENTS}

This work was financially supported by the Czech Science Foundation, project No. 18-19213Y. M.K. gratefully acknowledges financial support from the Operational Programme Research, Development and Education, The Ministry of Education, Youth and Sports (OP RDE, MEYS), grant No.

CZ.02.1.01/0.0/0.0/16_013/0001794. M.Z. gratefully acknowledges financial support by the Charles University under the project GA UK No. 410119.

\section{REFERENCES}

[1] WITTE, F., FISCHER, J., NELLESEN, J., VOGT, C., VOGT, J., DONATH, T., and BECKMANN, T. In vivo corrosion and corrosion protection of magnesium alloy LAE442. Acta Biomaterialia. 2010. vol. 6, pp 1792-1799.

[2] KRAUSE, A., VON DER HÖH, N., BORMANN, D., KRAUSE, C., BACH, F.-W., WINDHAGEN, H., and MEYERLINDENBERG, A. Degradation behaviour and mechanical properties of magnesium implants in rabbit tibiae. Journal of Materials Science. 2010. vol. 45, pp. 624-632.

[3] RÖSSIG, C., ANGRISANI, N., HELMECKE, P., BESDO, S., SEITZ, J.M., WELKE, B., FEDCHENKO, N., KOCK, $\mathrm{H}$., and REIFENRATH, J. In vivo evaluation of a magnesium-based degradable intramedullary nailing system in a sheep model. Acta Biomaterialia. 2015. vol. 25, pp. 369-383.

[4] DIEKMANN, J., BAUER, S., WEIZBAUER, A., WILLBOLD, E., WINDHAGEN, H., HELMECKE, P., LUCAS, A., REIFENRATH, J., NOLTE, I., and EZECHIELI, M. Examination of a biodegradable magnesium screw for the reconstruction of the anterior cruciate ligament: A pilot in vivo study in rabbits. Materials Science and Engineering C. 2016. vol. 59, pp. 1100-1109.

[5] WITKIN, D.B. and LAVERNIA, E.J. Synthesis and mechanical behavior of nanostructured materials via cryomilling. Progress in Materials Science. 2006. vol. 51, pp. 1-60.

[6] MINÁRIK, P., LUKÁČ, F., CINERT, J., ŠAŠEK, S., and KRÁL, R. Effect of sintering temperature on microstructure and mechanical properties of AE42 magnesium alloy prepared by spark plasma sintering. In: METAL 2018 - 27th International Conference on Metallurgy and Materials. 2018. pp. 1401-1406.

[7] MINÁRIK, P., STRÁSKÝ, J., VESELÝ, J., LUKÁČ, F., HADZIMA, B., and KRÁL, R. AE42 magnesium alloy prepared by spark plasma sintering. Journal of Alloys and Compounds. 2018. vol. 742, pp. 172-179.

[8] TIAN, X., WANG, L.M., WANG, J.L., LIU, Y.B., AN, J., and CAO, Z.Y. The microstructure and mechanical properties of Mg-3Al-3RE alloys. Journal of Alloys and Compounds. 2008. vol. 465, pp. 412-416

[9] VON MISES, R. Mechanik der plastischen Formänderung von Kristallen. Zeitschrift für Angewandte Mathematik und Mechanik. 1928. vol. 8, pp. 161-185.

[10] AGNEW, S.R., TOMÉ, C.N., BROWN, D.W., HOLDEN, T.M., and VOGEL, S.C. Study of slip mechanisms in a magnesium alloy by neutron diffraction and modeling. Scripta Materialia. 2003. vol. 48, pp. 1003-1008.

[11] JANEČEK, M., KRÁL, R., DOBROŇ, P., CHMELÍK, F., F., ŠUPÍK, V., and HOLLÄNDER, F. Mechanisms of plastic deformation in AZ31 magnesium alloy investigated by acoustic emission and transmission electron microscopy. Materials Science and Engineering: A. 2007. vol. 462, pp. 311-315.

[12] HEIPLE, C.R. and CARPENTER, S.H., Acoustic emission produced by deformation of metals and alloys - A review, part I and II. Journal of Acoustic Emission. 1987. vol. 6, pp. 177-237. 